\title{
Advanced medullary thyroid cancer treated with Sorafenib: A case report
}

\author{
M. Delgado, M. Legerén, J M. J urado, I . Zarcos, MJ . Sánchez, R. Fonseca, A. Villaescusa, F.Gálvez, \\ A. Calvo, J L. García-Puche \\ Medical Oncology Service, San Cecilio University Hospital, Granada, Spain \\ Correspondence: Mayte Delgado. Address: Servicio de Oncología Médica, Hospital Universitario San Cecilio, Avda. \\ Doctor Olóriz, 16, 18012- Granada, Spain. E-mail: maitechu22@hotmail.com
}

Received: October 10, 2012

DOI : $10.5430 /$ jst.v3n1p34

Accepted: December 9, 2012

URL: http://dx.doi.org/10.5430/jst.v3n1p34

\section{Abstract}

Background: Medullary thyroid carcinoma (MTC) accounts for 5\% of all thyroid carcinomas. As no effective systemic therapy exists, surgery is the only curative treatment for MTC. In the last few years, several clinical trials have tested the efficacy of new multi-targeted agents such as sorafenib, vandetanib, motesanib, sunitinib and pazopanib in patients with metastatic MTC.

Summary: In June 2010, a 38-year-old male patient complained of pain on swallowing and coughs. Physical examination detected a hard nodule of $2 \mathrm{~cm}$ on the left side of his neck. A fine-needle aspiration of it yielded evidence of carcinoma. A computed tomography scan showed multiple lyphadenopathies. In August 2010, the patient underwent an incomplete thyroidectomy and received radiotherapy. In spite of that, he was still unable to swallow either solids or liquids, and suffered dyspnoea on moderate exertion. In May 2011, the patient started receiving sorafenib and levothyroxine. After 20 days, his clinical symptoms were less severe and palpable lymphadenopathies shrank by $50 \%$. After 5 months, the patient still had no dysphagia or dyspnoea, but developed fatigue and elevated transaminases. Sorafenib was discontinued and the liver was examined by ultrasonography with no abnormal findings. After a two-week rest period, the patient resumed sorafenib from November 2011 to December 2012, achieving a clinical, biochemical and radiological response.

Conclusion: This case provides limited evidence for a potential role for sunitinib in the treatment of patients with metastatic MTC.

\section{Key words}

Gene mutations, Multiple endocrine neoplasia type 2A, Proto-oncogenes, Thyroid neoplasms, Tyrosine kinase inhibitors

\section{I ntroduction}

Medullary thyroid cancer (MTC) accounts for $5 \%$ of all carcinomas of the thyroid. Its origin may be sporadic (80-90\%) or familial (10-20\%). Familial MTC is transmitted in an autosomal dominant fashion and is related to multiple endocrine neoplasia (MEN) type 2A (medullary carcinoma, phaeochromocytoma and hyperparathyroidism) and MEN type 2B (medullary carcinoma, phaeochromocytoma and neuroma) syndrome ${ }^{[1]}$. 
As no effective systemic therapy exists, surgery is the only curative treatment for MTC. Unlike differentiated thyroid cancers, MTC cells do not take up radioiodine, so no suppression of thyroid-stimulating hormone (TSH) occurs. The 5 -year survival rate of patients with metastatic MTC is $25 \%$ and they respond poorly to chemotherapy, radiotherapy and metabolic treatment ${ }^{[2]}$.

In the last few years, many clinical trials have tested the efficacy of new multi-targeted agents, including sorafenib, vandetanib, motesanib, sunitinib and pazopanib, in patients with metastatic MTC. The oral drug sorafenib is a multi-kinase inhibitor with potent activity against Raf, vascular endothelial growth factor receptor (VEGFR) 2 and 3, platelet-derived growth factor receptor (PDGFR) and Ret kinase ${ }^{[3]}$.

We present the case of a young patient with advanced thyroid cancer from the beginning and to produce significant symptomatology.

\section{Case report}

A 38-year-old male patient had a past medical history of obesity and sleep apnoea syndrome. Notable aspects of his family history were a mother diagnosed with colon cancer, one paternal uncle diagnosed with stomach cancer and another paternal uncle diagnosed with cancer of the pancreas.

Figure 1. Post-surgical CT image, showing enlargement of the left lobe of the thyroid, a mediastinal mass measuring $5.5 \mathrm{~cm}$ surrounding the trachea, and multiple supraclavicular lymphadenopathies.

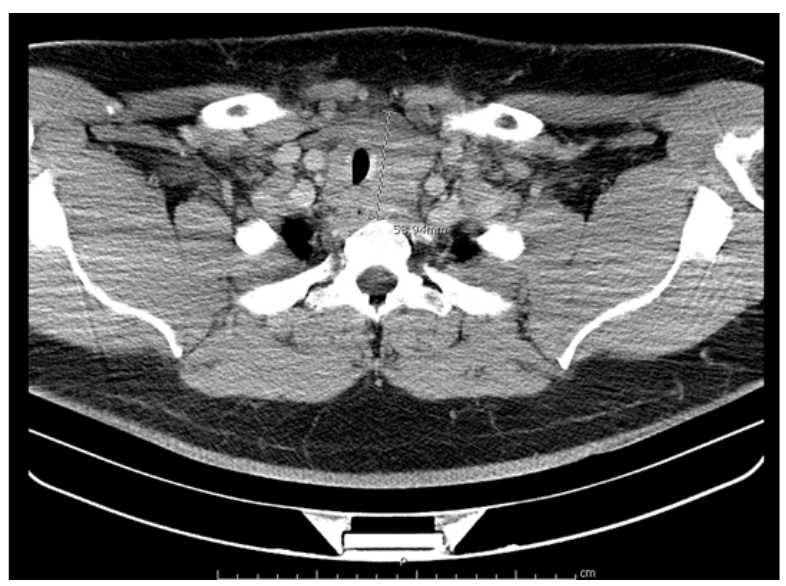

In June 2010, the patient complained of pain on swallowing and coughs. Physical examination detected a hard nodule, measuring $2 \mathrm{~cm}$, on the left side of his neck. No abnormalities were apparent on fibre-optic bronchoscopy. Fine-needle aspiration (FNA) of the cervical lymphadenopathy yielded histological evidence suggestive of carcinoma. A computed tomography (CT) scan of the neck and chest was done to assess spread. This showed multiple cervical, submandibular, submental and supraclavicular lymphadenopathies, together with enlargement of the left lobe of the thyroid, extending to form a $15 \times 5.5 \mathrm{~cm}(\mathrm{~L} \times \mathrm{T})$ mediastinal mass surrounding the trachea.

Laboratory tests showed abnormal values for TSH (47.52 $\mu \mathrm{IU} / \mathrm{mL}$, normal 0.4-4 $\mu \mathrm{IU} / \mathrm{mL})$ and carcinoembryonic antigen (CEA) $(166.7 \mathrm{ng} / \mathrm{mL}$, normal $5 \mathrm{ng} / \mathrm{mL}$ ) with a calcitonin concentration of over $2000 \mathrm{pg} / \mathrm{mL}$ (normal inferior to $10 \mathrm{pg} / \mathrm{mL}$ ). Other parameters tested were within normal limits, including triiodothyronine $\left(\mathrm{T}_{3}\right)$ (normal 70-210 ng/dL) and thyroxine $\left(\mathrm{T}_{4}\right)$ (normal $4.7-13 \mathrm{ng} / \mathrm{dL}$ ).

In August 2010, the patient underwent an incomplete thyroidectomy because of tumour invasion of the trachea and mediastinal lymphadenectomy with R2 surgery. Histological findings were consistent with MTC with metastasis to one of 
three mediastinal lymph nodes isolated. The patient then had 60 Gy of radiotherapy, finishing treatment in February 2011. Tolerance was moderate, and included the development of grade 2 mucositis.

Figure 2. CT image obtained 6 months after sorafenib treatment began. There is a $4.5 \mathrm{~cm}$ mediastinal mass surrounding the trachea, but the oesophageal lumen is visible. Supraclavicular and mediastinal lymphadenopathies can be seen.

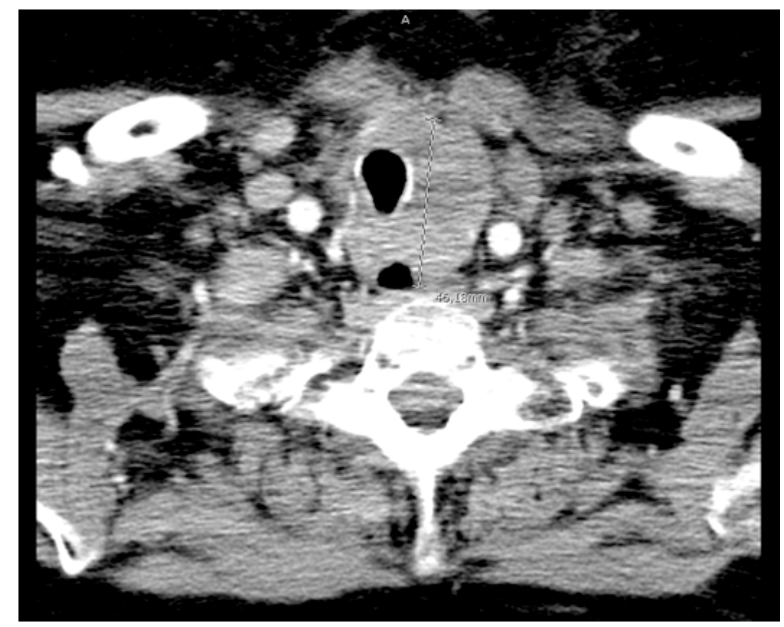

Molecular tests for the RET proto-oncogene detected no mutations in the coding regions examined. A repeat CT scan showed persistence of cervical and jugular lymphadenopathies, as well as the peritracheal mass, now measuring $10 \times 5.5$ $\mathrm{cm}$ (Figure 1). Further laboratory tests showed a CEA value of $653 \mathrm{ng} / \mathrm{mL}$ and a CA 19-9 concentration of $995 \mathrm{U} / \mathrm{mL}$. Clinically, the patient was unable to swallow either solids or liquids, and suffered dyspnoea on moderate exertion. Physical examination detected cervical lymphadenopathies up to $4 \mathrm{~cm}$ in size.

In May 2011, the patient started treatment with sorafenib (400 mg every 12 hours) and levothyroxine (150 mg per day). Twenty days after starting treatment, his clinical symptoms (gastrointestinal and respiratory) were less severe, the palpable lymphadenopathies had shrunk by 50\% (the largest ones measuring $2 \mathrm{~cm}$ ), and tumour marker concentrations had fallen. After 5 months of treatment, the patient still had no dysphagia or dyspnoea, but developed fatigue and elevated transaminases (aspartate aminotransferase: $86 \mathrm{U} / \mathrm{l}$; alanine aminotransferase: $411 \mathrm{U} /$; gamma-glutamyl transpeptidase: 3,859 U/l). Sorafenib was discontinued and the liver was examined by ultrasonography, with no abnormal findings. After a two-week rest period, the patient was reassessed by CT. This showed shrinkage of the mediastinal mass, along the anteroposterior diameter, allowing the oesophageal lumen to be seen (Figure 2).

Figure 3. CT image obtained 16 months after sorafenib treatment began. There is a $4.5 \mathrm{~cm}$ mediastinal mass surrounding the trachea, but the oesophageal lumen is visible.

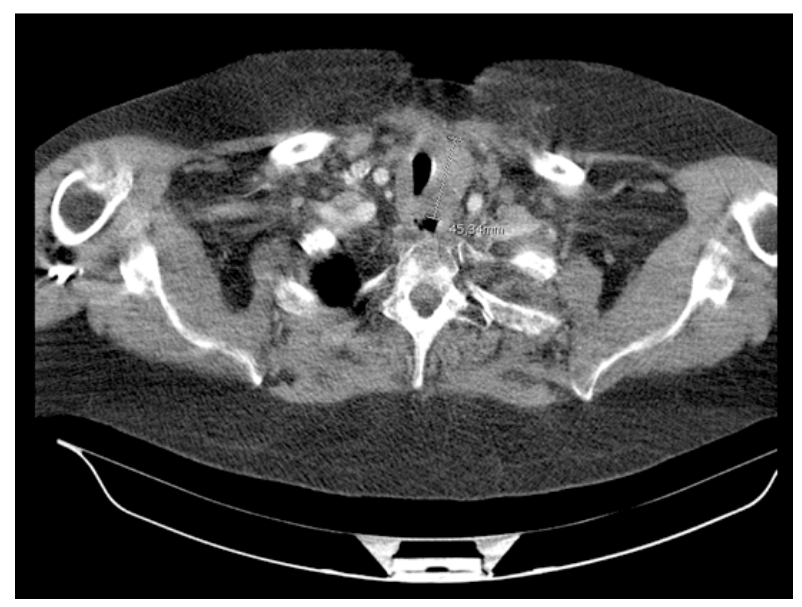


As there was an improvement in his fatigue and liver profile, the patient resumed sorafenib (600 mg per day). He continued to take this from November 2011 to December 2012, achieving a clinical, biochemical (CEA: $383 \mathrm{ng} / \mathrm{mL}$; CA 19-9: 221 $\mathrm{U} / \mathrm{mL}$ ) and radiological response (Figure 3). Since beginning sorafenib treatment in May 2011, the patient has remained stable for 19 months in total, gaining substantial clinical benefit without suffering any severe toxicity.

\section{Discussion}

Differentiated thyroid cancers, such as papillary and follicular cancers, are potentially curable with surgery and radioiodine ablation. In contrast, undifferentiated cancers like MTC are characterised by a poor response to these treatments.

In 2008, results were published from a phase II clinical trial involving 30 thyroid cancer patients with disease progression after radioiodine therapy, who were treated with $400 \mathrm{mg}$ of sorafenib every 12 hours. Their median progression-free survival (PFS) was 18 months, although most patients included had well-differentiated thyroid carcinomas ${ }^{[4]}$. In 2009, results were published from another phase II clinical trial, involving 41 patients with papillary thyroid cancer treated with the same dose of sorafenib, in whom a median PFS of 15 months was observed ${ }^{[3]}$. Another phase II clinical trial, published in 2010, involved 16 patients with advanced MTC given sorafenib, who achieved a median PFS of 17.9 months. These patients could have had chemotherapy or radiotherapy previously ${ }^{[5]}$.

\section{Conclusion}

Our patient is currently still taking sorafenib, after 19 months of treatment. He has none of the side effects described in the literature and is obtaining substantial clinical benefit.

\section{References}

[1] Hoff AO, Hoff PM. Medullary thyroid carcinoma. Hematol Oncol Clin North Am. 2007; 21: 475-488; viii. PMid:17548035 http://dx.doi.org/10.1016/j.hoc.2007.04.002

[2] Schlumberger M, Abdelmoumene N, Delisle MJ et al. Treatment of advanced medullary thyroid cancer with an alternating combination of 5 FU-streptozocin and 5 FU-dacarbazine. The Groupe d'Etude des Tumeurs a Calcitonine (GETC). Br J Cancer. 1995; 71: 363-365. PMid:7530987 http://dx.doi.org/10.1038/bjc.1995.73

[3] Kloos RT, Ringel MD, Knopp MV et al. Phase II trial of sorafenib in metastatic thyroid cancer. J Clin Oncol. 2009; 27 : 1675-1684. PMid:19255327 http://dx.doi.org/10.1200/JCO.2008.18.2717

[4] Gupta-Abramson V, Troxel AB, Nellore A et al. Phase II trial of sorafenib in advanced thyroid cancer. J Clin Oncol. 2008; 26: 4714-4719. PMid:18541894 http://dx.doi.org/10.1200/JCO.2008.16.3279

[5] Lam ET, Ringel MD, Kloos RT et al. Phase II clinical trial of sorafenib in metastatic medullary thyroid cancer. J Clin Oncol. 2010; 28: 2323-2330. PMid:20368568 http://dx.doi.org/10.1200/JCO.2009.25.0068 